\title{
Effect of sub MIC for Imipenem, Amikacin and Cefixime on Growth and Swarming of Proteus mirabilis
}

\author{
Hayder Hamzah Ibrahim ${ }^{1 *}$, Naeem Rahman aljeburi ${ }^{2}$, Muna Sabbar Jebar ${ }^{1}$, Mustafa \\ Ali Gayeb ${ }^{1}$, Saher Saleh Mahdi ${ }^{1}$, Hadeer Ali Kudder ${ }^{1}$, and Marwa Majed Naseer ${ }^{1}$ \\ ${ }^{1}$ Department of Medical Analysis, Babylon Technical Institute, Al-Furat Al-Awsat Technical University, Babylon, \\ Iraq. ${ }^{2}$ Hilla General teaching Hospital, Babylon, Iraq.
}

\begin{abstract}
The purpose of the present study is to evaluate the effect sub minimum inhibitory concentration (MIC) of imipenem, amikacin and cefixime on growth and swarming of Proteus mirabilis. 10 clinical isolates of Proteus mirabilis were isolated from patients suffering from urinary tract infection. 3 types of antibiotics include imipenum, amikacin and cefixime were used in present study to detect their ability to inhibition the swarming of $P$. mirabilis. Each isolate were inoculated on a series of nutrient agar containing different concentrations $(60,30,15,7.5,3.75,1.8$ and $0.9 \mu \mathrm{g} / \mathrm{ml})$ of imipenem, cefixime and amikacin. All these were incubated over night at $37^{\circ} \mathrm{C}$, after that the cultivated bacterial growth examined to determine the effect of each antibiotic on growth and swarming of $P$. mirabilis. The results showed that the $0.93 \mu \mathrm{g} / \mathrm{ml}$ of imipenem have ability to inhibit the swarming of all isolates $(100 \%)$ and it have not any effect on growth (bacterial growth $100 \%)$ whereas the same concentration of cefixime inhibit $90 \%$ of isolate and also have not any effect on growth (bacterial growth $100 \%$ ). The results of amikacin showed that the $0.93 \mu \mathrm{g} / \mathrm{ml}$ of antibiotic inhibit the swarming $50 \%$ of isolate and the bacterial growth was $100 \%$. Imipenem have good inhibiter effect on Proteus mirabilis swarming at concentration of $0.93 \mu \mathrm{g} / \mathrm{ml}$ and we suggest that we can use this antibiotic to prepare cultural media to separate mixed culture contain $P$. mirabilis.
\end{abstract}

Keywords: Urinary tract infection, Proteus, swarming, Imipenem, Amikacin, Cefixime.

\footnotetext{
*Correspondence: altee221551@gmail.com; muna.jebar@yahoo.com
}

(Received: 21 September 2018; accepted: 04 November 2018)

Citation: Hayder Hamzah Ibrahim, Naeem Rahman aljeburi, Muna Sabbar Jebar, Mustafa Ali Gayeb, Saher Saleh Mahdi, Hadeer Ali Kudder, and Marwa Majed Naseer, Effect of sub MIC for Imipenem, Amikacin and Cefixime on Growth and Swarming of Proteus mirabilis, J Pure App/ Microbiol., 2018; 12(4):2241-2244. http://dx.doi.org/10.22207/JPAM.12.4.63

(c) The Author(s) 2018. Open Access. This article is distributed under the terms of the Creative Commons Attribution 4.0 International License which permits unrestricted use, sharing, distribution, and reproduction in any medium, provided you give appropriate credit to the original author(s) and the source, provide a link to the Creative Commons license, and indicate if changes were made. 


\section{INTRODUCTION}

The $P$. mirabilis gram negative motile aerobic bacilli, does not ferment lactose. It produces urease, resulting in rapid hydrolysis of urea, with liberation of ammonia. It tends to "swarm" spreading rapidly over the surface of solid media. P. mirabilis formalizes of cosmopolitan microorganisms: inhabits contaminated water, soil and intestinal tract of mammals (Armbrusterand Mobley, 2012). It is the second most common causative agent of UTIs, causes cystitis and pyelonephritis in patients with indwelling catheters (Klevens, et al., 2007: Mathur, et al., 2005). Once bacteria have colonized the catheter can rapidly reach the bladder and potentially establish a UTI (Jacobsen, et al., 2008: Hooton, et al., 2010; Jacobsen, et al. 2008).

Swarming behavior is a remarkable feature of development of $P$. mirabilis catheter related infection. Swarming is described as the information of the concentric zones of bacterial growth can able to cover the whole surface of sold culture medium (Belas \& Flaherty, 1994). This phenomena cause's difficult of isolation of other organisms from mixed cultures involving $P$. mirabilis. The swarming of $P$. mirabilis in mixed culture is a continual source of trouble to bacteriologists. A method by which could control it without affecting the growth of more delicate organisms would be of great value.

A number of compounds have been proposed as additives to solid media to prevent the swarming of $P$. mirabilis, Whitby, et al., 1945; MacConkey, et al., 1999; Sokokski, and Stapert,1963 and Williams, 1973, have been used numerous media to prevent this swarming, among these are very dry plate, MacConkey medium containing bile salt, ferrous ions and P- nitrophenyl glycerin. And there is a study for Malik, et al., 2015 they can inhibit swarming of $P$. mirabilis by plant extraction of $P$. graveolens essential oil and they suggests its potential to be developed as a product for preventing $P$. mirabilis infections. Also Mamunur et al. 2014 use plant extraction of Emblica officinalis and Tamarindus indica to inhibit P. mirabilis swarming.

This study is aimed to evaluate the effect of imipenem, amikacin and cefixime on swarming of $P$. mirabilis to be using new medium that can prevent $P$. mirabilis swarming.

\section{MATERIAL AND METHODS}

10 clinical isolates of $P$. mirabilis collect from patients suffering from urinary tract infection. 3 types of antibiotics include imipenem, amikacin and cefixime were used in present study to detect their ability to inhibit the swarming of $P$. mirabilis. Each isolate were inoculated on a series of nutrient agar containing different concentrations (60, 30, $15,7.5,3.75,1.8$ and $0.9 \mu \mathrm{g} / \mathrm{ml}$ ) of imipenem, cefixime and amikacin. Also control plate contain nutrient agar only was used. All these are incubate over night at $37^{\circ} \mathrm{C}$ in aerobic conditions, after that the culture examined to determine the effect of each antibiotic on growth and swarming of Proteus mirabilis.

\section{RESULTS AND DISCUSSION}

There are different ways to inhibit swarming of $P$. mirabilis such as increase the concentration of agar $(2.5-3.0 \% \mathrm{w} / \mathrm{v})$ or coalescent growth inhibitors like boric acid (1 in 100), sodium azide ( 1 in 5000), chloral hydrate (1 in 500) and sulphonamide. Use of these chemicals may prevent the growth of other pathogenic bacteria. Swarming of $P$. mirabilis can also be inhibited on media like Deoxycholate citrate agar (DCA) and MacConkey agar which contains bile salts. In the present study imipenem, cefixime and amikacin used to prevent the swarming of $P$. mirabilis without affecting the growth bacteria.

The results showed that the $7.5 \mu \mathrm{g} /$ $\mathrm{ml}$ is the MIC of imipenem minimum inhibitory concentration which can inhibit growth all isolates and $3.75 \mu \mathrm{g} / \mathrm{ml}$ inhibit growth of $90 \%$ of isolates and $1.87 \mu \mathrm{g} / \mathrm{ml}$ inhibit growth of $40 \%$ of isolates in addition to that the results showed that the $0.93 \mu \mathrm{g} / \mathrm{ml}$ of imipenem have ability to inhibit the

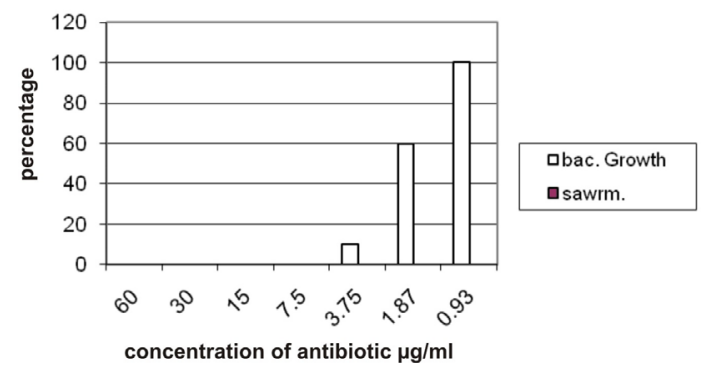

Fig. 1. Effect of Imipenem on growth and swarming of Proteus mirabilis 
swarming of all isolates (100\%) and it have not any effect on growth (bacterial growth 100\%) figure 1.

Also the results showed that the $60 \mu \mathrm{g} /$ $\mathrm{ml}$ is the MIC of cefixime that can inhibit growth of all isolates and the concentration 30, $15 \mu \mathrm{g} /$ $\mathrm{ml}$ can inhibit growth $90 \%$ of isolates as shown in figure 2, whereas the $0.93 \mu \mathrm{g} / \mathrm{ml}$ of cefixime inhibit swarming of $90 \%$ of isolate and also have not any effect on growth (bacterial growth 100\%).

The results of amikacin revealed that the $15 \mu \mathrm{g} / \mathrm{ml}$ is the MIC which can inhibit growth of all isolates and the $7.5 \mu \mathrm{g} / \mathrm{ml}$ inhibit growth of $90 \%$ of isolates and the results revealed that the 0.93 $\mu \mathrm{g} / \mathrm{ml}$ of amikacin inhibit the swarming $50 \%$ of isolate and the bacterial growth was $100 \%$ at this concentration (Figure 3).

There are various studies that deal with inhibition of $P$. mirabilis swarming by using chemical compound (Rudolf, et al., 1966; Alwen \& Smith, 1976; Vanasten \& Gastra, 1999) but few studies deal with using of antibiotic to inhibition of $P$. mirabilis swarming.

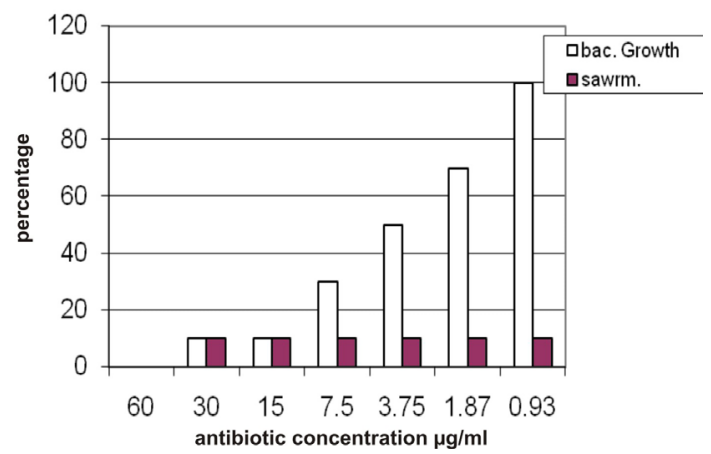

Fig. 2. Effect of sefixime on growth and swarming of Proteus mirabilis

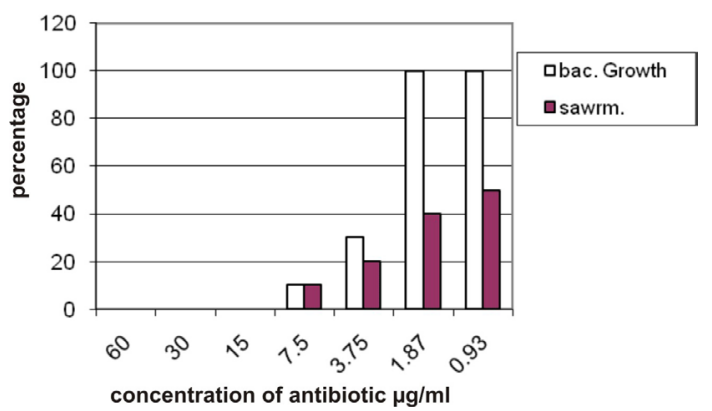

Fig. 3. Effect of amikacin on growth and swarming of Proteus mirabilis
Our results are agree with results of Tawfik et al., 1997 they reported that the exposure of $P$. mirabilis cells to sub minimal inhibitory concentrations of amikacin or gentamicin causes the inhibition of swarming and motility of $P$. mirabilis also they found the amikacin significantly reduced adhesion of $P$. mirabilis to human uroepithelial cells.

Also, Intisar, et al. 2006 recorded that tetracycline also shows good suppression effect on Proteus spp. swarming but in high concentration. Molinari et al., (1992) showed that the sub-MICs of azithromycin prevent motility of P.mirabilis and this inhibition is due to the absence of flagella and (Sato et al., 2000) recorded that the (erythromycin, clarithromycin, azithromycin) have inhibitory effect on motility of $P$. mirabilis.

\section{REFERENCES}

1. Alwen, J. \& Smith, D.G., Medium to Suppress Swarming of Proteus spp J. Appl. Bacteriol. 1976; 30:389-394.

2. Armbruster and Mobley. Merging mythology and morphology: the multifaceted lifestyle of Proteus mirabilis. Nat. Rev. Microbiol; 2012; 10:743- 754.

3. Belas, R. \& Flaherty, D., Sequence and Genetic Analysis of Multiple Flagellin-encoding Genes From P. mirabilis. Gene, 1994; 148: 33-41.

4. Hooton, T.M.; Bradley, S.F.; Cardenas, D.D.; Colgan, R.; Geerlings, S.E.; Rice, J.C.; Saint, S.; Schaeffer, A.J.; Tambayh, P.A.; Tenke, P.; Nicolle, L.E. Diagnosis, prevention, and treatment of catheter-associated urinary tract infection in adults: 2009 international clinical practice guidelines from the Infectious Diseases Society of America. Clin. Infect. Dis. 2010; 50: 625-663.

5. Intisar, A.; Muna, A.; Nisreen, A. and Ahmed, A. Effect of sub-mics of some antimicrobial agents on swarming of proteus spp. Al-Taqani, 2006; 19 (1): 6-11.

6. Jacobsen, S.M.; Stickler, D.J.; Mobley H.L.; Shirtliff, M.E. Complicated catheter-associated urinary tract infections due to Escherichia coli and Proteus mirabilis. Clin. Microbiol. Rev. 2008; 21: 26-59.

7. Klevens, R.M.; Edwards, J.R.; Richards, C.L.; Horan, T.C.; Gaynes, R.P.; Pollock, D.A.; Cardo, D.M. Estimating health care-associated infections and deaths in US hospitals, 2002. Public Health Rep. 2007; 122: 160-166.

8. MacConkey, M., Mackie and McCartney. Handbook of Bacteriology, Livingstone, London, 
UK, 1905. Cited by: Hernandez. E.: Ramisse, F.; Cavallo, J., "Abolition of swarming of Proteus" J. Clin. Microbiol. 1999; 37:3435-3438.

9. Malik, T.; Singh, P.; Pant, S.; Chauhan, N.; Lohani, H.; Kumar, V.; Swarup, S. Inhibition of swarming behaviour in Proteus mirabilis by Pelargonium graveolens essential oil, Bangladesh Journal of Medical Science. 2015; 14 (4).

10. Mamunur, R.; Abdul Wadud, and Aktar, U. Potent Inhibition of swarming growth of Uropathogenic Proteus Bacteria by Ethanolic extracts of Emblica officinalis fruit and Tamarindus indica bark. International Research Journal of Biological Sciences. 2014; 3(9): 57-64.

11. Mathur, S.; Sabbuba, N.A.; Suller, M.T.; Stickler, D.J.; Feneley, R.C. Genotyping of urinary and fecal Proteus mirabilis isolates from individuals with long-term urinary catheters. Eur. J. Clin. Microbiol. Infect. Dis. 2005; 24:643-644.

12. Molinari, G.; Paglia, P. and Schito, G. Inhibition of Motility of $P$. eruginosa and $P$. mirabilis in sub inhibitory concentration of azithromycin. Eur. J. Clin. Microbiol. Infec. Dis. 1992; 11, 469-471.

13. Rudolf, K.; Johannes, M. and Renate, L. Inhibition of Swarming of Proteus by Sodium Tetradecyl Sulfate, 3-Phenethyl Alcohol, and
p-Nitrophenylglycerol, Applied microbiology, 1966; 14(6): 873-879.

14. Sato, k.; Linuma, Y.; Hasegawa, T.; Yamashino, T. and Otha, M., "Effect of Subinhibitory concentrations of macrolides on expression of flagellin in P. aeruginosa \& P. mirabilis" Antimicrob.Agents.Chemother. 2000; 44(10): 2869-2872.

15. Sokokski, W.T. and Stapert, E.M., "Medium for the Control of Bacterial Swarmer" J. bacterial. 1963; 85: 718.

16. Tawfik, A.F.; Ramadan, M.A. ·and Shibl, A.M. Inhibition of Motility and Adherence of Proteus mirabilis to Uroepithelial Cells by Subinhibitory Concentrations of Amikacin Chemotherapy, 1997; 43:424-429

17. Vanasten, F.J. \& Gastra, W., "Urea Restrains Swarming of P. mirabilis" J. Clin. Microbiol. 1999; 37(5), pp: 1625.

18. Whitby, L.; Churchill and Churchill, A. London, Cited by: Hernandez, E.; Ramisse, F.; Carallo, J.," Abolition of swarming of Proteus ".J. Clin. Microbiol. 1945; 37, 3435-3438, 1999.

19. Williams, F.D. "Abolition of Swarming of Proteus by P-nitrophenyl glycerin general properties" Appl. Microbiol., 1973; 25, 745-750. 